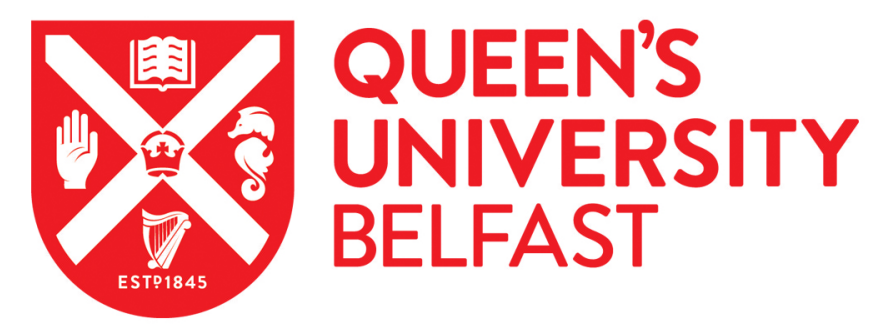

\title{
lonothermal, microwave-assisted synthesis of indium(III) selenide
}

Tyrrell, S., Swadzba-Kwasny, M., \& Nockemann, P. (2014). Ionothermal, microwave-assisted synthesis of indium(III) selenide. Journal of Materials Chemistry A, 2(8), 2616-2622. https://doi.org/10.1039/c3ta14478j

Published in:

Journal of Materials Chemistry A

Document Version:

Publisher's PDF, also known as Version of record

Queen's University Belfast - Research Portal:

Link to publication record in Queen's University Belfast Research Portal

Publisher rights

(C) 2013 The Authors

This is an open access article published under a Creative Commons Attribution License (https://creativecommons.org/licenses/by/3.0/), which permits unrestricted use, distribution and reproduction in any medium, provided the author and source are cited.

\section{General rights}

Copyright for the publications made accessible via the Queen's University Belfast Research Portal is retained by the author(s) and / or other copyright owners and it is a condition of accessing these publications that users recognise and abide by the legal requirements associated with these rights.

Take down policy

The Research Portal is Queen's institutional repository that provides access to Queen's research output. Every effort has been made to ensure that content in the Research Portal does not infringe any person's rights, or applicable UK laws. If you discover content in the Research Portal that you believe breaches copyright or violates any law, please contact openaccess@qub.ac.uk. 
Cite this: J. Mater. Chem. A, 2014, 2 , 2616

Received 1st November 2013 Accepted 3rd December 2013 DOI: $10.1039 / c 3 t a 14478 j$

www.rsc.org/MaterialsA

\section{lonothermal, microwave-assisted synthesis of indium(III) selenide}

\author{
Sophie Tyrrell, Małgorzata Swadźba-Kwaśny and Peter Nockemann*
}

\begin{abstract}
Microcrystalline indium(III) selenide was prepared from a diphenyl diselenide precursor and a range of chloroindate(III) ionic liquids via a microwave-assisted ionothermal route; this is the first report on the use of either microwave irradiation or ionic liquids to prepare this material. The influence of the reaction temperature, dilution with a spectator ionic liquid and variation of the cation and the anion of the ionic liquid on the product morphology and composition were investigated. This resulted in a time-efficient and facile one-pot reaction to produce microcrystalline indium(III) selenide. The product formation in the ionic liquids has been monitored using Raman spectroscopy. The products have been characterised using PXRD, SEM and EDX. Advantages of this new route, such as the ease of solubilisation of all reactants into one phase at high concentration, the negligible vapour pressure irrespective of the reaction temperature, very fast reaction times, ease of potential scale-up and reproducibility are discussed.
\end{abstract}

\section{Introduction}

Indium(III) selenide is a black crystalline n-type, III-VI layered semiconductor with a direct band gap of $1.7 \mathrm{eV} .^{1}$ The band gaps of III-VI layered semiconductors are generally narrow at room temperature, which makes them attractive compounds for solar energy conversion and optoelectronic devices ${ }^{2,3}$ and therefore, have potential in solar energy conversion applications. ${ }^{4}$ To date they have been studied as precursors to copper indium selenide, CIS, as an optical recording medium, a polarizer for optoelectronics and in Li-collated form for battery applications. ${ }^{5}$

Structurally, $\mathrm{In}_{2} \mathrm{Se}_{3}$ comprises primitive layers of four atomic planes, Se-In-In-Se; the selenium atoms form two-dimensional hexagonally close-packed sheets, which provides the crystal with the hexagonal structure. ${ }^{5}$ The two most common forms of crystalline $\operatorname{In}_{2} \mathrm{Se}_{3}$ are the $\alpha$ (layered structure) and $\gamma$ (the 'defect wurtzite structure'); ${ }^{6}$ other commonly known forms include the $\beta$ and $\delta$ phases, ${ }^{7}$ as well as the recently discovered $\kappa$ phase (anisotropic structure). ${ }^{8}$ Depending on the synthetic technique and reaction conditions, one of the crystalline forms of indium(III) selenide is produced, each form having a unique range of electronic and structural properties. For example, $\alpha$ $\mathrm{In}_{2} \mathrm{Se}_{3}$ has cation vacancies, which form a plane that results in weak Se-Se bonding and anisotropic electronic properties. $\mathrm{In}_{2} \mathrm{Se}_{3}$ is an anisotropic hexagonal or rhombohedral semiconductor that tends to have high resistivity. Importantly, when low reaction temperatures are implemented, indium selenide(II) crystals with a zinc blende structure are formed, while at higher temperatures hexagonal crystals of $\mathrm{In}_{2} \mathrm{Se}_{3}$ are obtained. In

QUILL, The Queen's University of Belfast, Belfast, BT9 5AG, UK. E-mail: p.nockemann@qub.ac.uk general, the presence of numerous forms of indium selenide, even in perfectly stoichiometric compositions, makes interpretation of exact product stoichiometry, electronic and optical data more difficult. ${ }^{8}$ The molar ratio of precursors and reaction temperature influence the type of indium(III) selenide produced, but not the shape and size of the product. ${ }^{9}$

Various atomic arrangements of indium(III) selenide materials have been reported in the literature: microporous (framework) materials of high structural complexity, ${ }^{10,11}$ open framework chalcogenides, noncluster-based 3D open-framework indium chalcogenides, ${ }^{12,13}$ with a range of morphologies also described, including, thin films ${ }^{1,4}$ and nanomaterials. ${ }^{14}$ Traditional synthetic routes involve long reaction times (up to 10 days $)^{43}$ with high temperatures, up to $450{ }^{\circ} \mathrm{C},{ }^{15}$ and high pressures, often combined with using hazardous organic solvents, such as ethylenediamine, hydrazine or 3,5-dimethylpyridine. These solvents are necessary due to the troublesome dissolution of elemental selenium, generally used as a precursor. ${ }^{16}$

In this contribution, we propose an innovative route to microcrystalline indium(III) selenide, taking advantage of possibilities offered by ionic liquid-based synthesis. Ionic liquids are salts, typically based on organic cations, with melting points below $100{ }^{\circ} \mathrm{C}$, and often much lower than ambient temperature. ${ }^{17,18}$ Among their common characteristics are negligible vapour pressure and ability to dissolve a wide range of organic and inorganic materials, ${ }^{19-22}$ with a solubility significantly higher than that exhibited for most organic solvents. ${ }^{23}$ Ionic liquids have an extraordinarily high solubility for metal halides when placed in highly polar Lewis acidic systems, even at room temperature. This has allowed for a low temperature one-pot synthesis of a range of chalcogenide 
materials. ${ }^{24}$ The excellent solubility allows for synthesis of nano, micro and macro-sized inorganic products, with new materials being possible due to the change from molecular to ionic solvent systems. ${ }^{21}$ This has led to the development of a new synthetic approach based on ionic liquids, named 'ionothermal' synthesis, ${ }^{21,25,26}$ in analogy to hydrothermal processes. In a typical ionothermal process, all reactants are dissolved in an ionic liquid, which is subsequently heated to allow the reaction to proceed, with ambient pressure maintained due to the non-volatile nature of ionic liquids.

Chlorometallate ionic liquids are a class of ionic liquids based on an organic cation and a chlorometallate anion. ${ }^{27}$ They are prepared by the reaction of an organic chloride salt with a metal chloride; various ratios of reactants may be used, which leads to different anionic speciation, as exemplified for the In(III) system in eqn (1)-(3). ${ }^{28}$

$$
\begin{aligned}
& 1[\text { cation }] \mathrm{Cl}+\mathrm{InCl}_{3} \rightarrow[\text { cation }]\left[\mathrm{InCl}_{4}\right] \\
& 2[\text { cation }] \mathrm{Cl}+\mathrm{InCl}_{3} \rightarrow[\text { cation }]_{2}\left[\mathrm{InCl}_{5}\right] \\
& 3[\text { cation }] \mathrm{Cl}+\mathrm{InCl}_{3} \rightarrow[\text { cation }]_{3}\left[\mathrm{InCl}_{6}\right]
\end{aligned}
$$

These anions remain in a dynamic equilibrium with each other, as shown in eqn (4).

$$
\left[\mathrm{InCl}_{5}\right]^{2-} \rightleftarrows\left[\mathrm{InCl}_{4}\right]^{-}+\left[\mathrm{InCl}_{6}\right]^{3-}
$$

Chlorometallate ionic liquids are excellent media for the synthesis of inorganic materials; besides 'regular' advantages of ionic liquids, they also act as a metal source, available in very high concentrations and with a tuneable coordination. ${ }^{29}$ To date, chlorometallate ionic liquids have been used in dual roles of solvents and precursors to prepare a range of inorganic materials: $\mathrm{Cu}{ }^{\mathrm{I}} \mathrm{Cl}$ nanoplatelets, ${ }^{30} \mathrm{In}^{0},{ }^{31} \mathrm{Au}^{0}$ and $\mathrm{Pd}^{0}$ nanoparticles $^{32}$ and complete families of semiconductor materials, such as $\left[\mathrm{Bi}_{2} \mathrm{Te}{ }_{2} \mathrm{Br}\right]\left[\mathrm{AlCl}_{4}\right],,^{33}\left[\left(\mathrm{Bi}_{4} \mathrm{Te}_{4} \mathrm{Br}_{2}\right)\left(\mathrm{Al}_{2} \mathrm{Cl}_{(6-x)} \mathrm{Br}_{x}\right)\right] \mathrm{Cl}_{2}$ and $\left[\mathrm{Bi}_{2} \mathrm{Se}_{2} \mathrm{Br}\right]\left[\mathrm{AlCl}_{4}\right]^{34}$ In many cases it is emphasised that the cation plays a significant role, acting as a templating and/or stabilising agent. ${ }^{30-32,35}$

Microwave-assisted synthesis may, in many cases, dramatically reduce the reaction time, and has been successfully implemented in the preparation of a variety of inorganic materials. ${ }^{36}$ Ionic liquids readily absorb microwave irradiation and do not increase vapour pressure upon rapid heating, hence are particularly suitable for fast-paced microwave-assisted synthesis. ${ }^{37}$

To our knowledge, neither ionic liquids and the ionothermal approach, nor microwave-based synthesis have been adopted to prepare indium(III) selenide. In this work, advantages of chlorometallate ionic liquids and microwave-assisted synthesis were combined to access microcrystalline indium(III) selenide in a fast, safe and elegant synthetic pathway.

\section{Experimental}

\section{Materials}

Indium(III) chloride, 99\%, anhydrous, and diphenyl diselenide, 99\%, and indium(III) selenide were purchased from Sigma-
Aldrich. Ionic liquid families: alkyl(trioctyl)phosphonium chloride, $\left[\begin{array}{lll}\mathrm{P}_{8} & 8 & 8\end{array}\right]$ Cl, and alkyl(trihexyl)phosphonium chloride, $\left[\mathrm{P}_{66} 6_{n}\right] \mathrm{Cl},(n=3,5,10,14,17$ and 18) were prepared as described elsewhere. ${ }^{38}$ 1-Octyl-3-methylimidazolium chloride, $\left[\mathrm{C}_{8} \mathrm{mim}\right] \mathrm{Cl}$, was prepared as previously reported. ${ }^{28}$

\section{Synthesis}

Synthesis of chloroindate(III) ionic liquids. Appropriate amounts of indium(III) chloride and a phosphonium or imidazolium chloride ionic liquid were placed in a round-bottomed flask containing a stirring bar. The flask was closed with a stopper and placed in a heating bath, and the mixture was stirred vigorously $\left(80^{\circ} \mathrm{C}\right.$, overnight). Pale yellow liquids were obtained in all cases.

Synthesis of bis(trifluoromethanesulfone)imide ionic liquid. $\left[\begin{array}{l}\mathrm{P}_{8} \quad 8 \quad 8 \quad 10\end{array}\right] \mathrm{Cl}(0.60 \mathrm{~g}, 1.097 \mathrm{mmol})$ was dissolved in $6 \mathrm{~cm}^{3}$ of dichloromethane. $\operatorname{LiNTf}_{2}(2.16 \mathrm{~g}, 7.526 \mathrm{mmol})$ was dissolved in $6 \mathrm{~cm}^{3}$ of water. Both solutions were poured into a roundbottomed flask $\left(250 \mathrm{~cm}^{3}\right)$ containing a stirring bar. The flask was closed with a stopper and the mixture was stirred vigorously overnight. Subsequently, the top (aqueous) layer was decanted, and the bottom (ionic liquid) layer was washed three times with an aqueous solution of $\operatorname{LiNTf}_{2}\left(0.02 \mathrm{~mol} \mathrm{~cm}{ }^{-3}\right)$ and ten times with deionised water. Remaining solvents were removed using a rotary evaporator $\left(80^{\circ} \mathrm{C}, 1 \mathrm{~h}\right)$ and then high vacuum $\left(80^{\circ} \mathrm{C}\right.$, overnight, $10^{-2}$ mbar).

Synthesis of indium(III) selenide. In a typical process, $\mathrm{Ph}_{2} \mathrm{Se}_{2}$ was added to a chloroindate(III) ionic liquid, in a $3: 4$ ratio, before being placed in the microwave reactor Anton Parr Monowave 300 for $1 \mathrm{~min}$. Reaction temperatures were varied between 200 and $280{ }^{\circ} \mathrm{C}$ (temperature measurement error by the IR probe was $\pm 10{ }^{\circ} \mathrm{C}$ ). The product formed was a suspension of a fine brown/black powder in an ionic liquid, and was subsequently washed with methanol and centrifuged to separate the particles from the ionic liquid.

\section{Characterisation}

Scanning electron microscopy (SEM) studies were carried out using a JEOL 6500F Field Emission and a Quanta FEG 250 Scanning Electron Microscope. Energy dispersive X-ray (EDX) analysis was carried out using Oxford Instruments INCA systems.

X-Ray diffraction (XRD) data were collected using a Siemens $\mathrm{D} 5000$ powder diffractometer with $\mathrm{Cu} \mathrm{K} \alpha$ radiation $(\gamma=1.542 \AA)$. Data were recorded from between $10^{\circ}$ and $60^{\circ}$ in steps of 0.0167 .

Raman spectra were recorded using a PerkinElmer RamanStation $400 \mathrm{~F}$ spectrometer, with a $785 \mathrm{~nm}$ focussed laser beam. All studied samples were placed in quartz cuvettes and analysed neat; ten scans of $5 \mathrm{~s}$ each were recorded.

\section{Results and discussion}

In the approach presented here, diphenyl diselenide was dissolved in a chloroindate(III) ionic liquid and exposed to microwave radiation to result directly in microcrystalline indium(III) 
selenide. The specific ratio of reagents $\left(3\right.$ moles of $\mathrm{Ph}_{2} \mathrm{Se}_{2}$ to 4 moles of ionic liquid with a $\left[\mathrm{InCl}_{4}\right]^{-}$anion to give an In : Se ratio of $2: 3$ ) was chosen to achieve the desirable stoichiometry of $\mathrm{In}_{2} \mathrm{Se}_{3}$. The metal-containing ionic liquid acts as a non-volatile solvent and reactant at the same time in an ionothermal process.

Under ambient conditions diphenyl diselenide was suspended in an ionic liquid, but upon heating between 50 and $60{ }^{\circ} \mathrm{C}$, all ionic liquids readily dissolved diphenyl diselenide, $\mathrm{Ph}_{2} \mathrm{Se}_{2}$, to form homogenous, orange/yellow solutions (Fig. 1a). Upon further heating ( 240 to $280{ }^{\circ} \mathrm{C}$ ), a brown to black suspension was formed, as shown in Fig. $1 \mathrm{~b}$.

Raman spectra of the solution of $\mathrm{Ph}_{2} \mathrm{Se}_{2}$ in the ionic liquid are compared to the spectra of the neat ionic liquid and pure $\mathrm{Ph}_{2} \mathrm{Se}_{2}$ (Fig. 2). The Raman spectrum of the neat ionic liquid displays vibrations at 224 and $114 \mathrm{~cm}^{-1}$, which are characteristic of the tetrahedral $\left[\mathrm{InCl}_{4}\right]^{-}$anion. ${ }^{39}$ For the spectrum of $\mathrm{Ph}_{2} \mathrm{Se}_{2}$ dissolved in the ionic liquid (Fig. 2a), peaks are evident for both the ionic liquid and the selenium precursor, and it appears that the $\mathrm{Ph}_{2} \mathrm{Se}_{2}$ simply dissolves in the ionic liquid, without coordination to the indium centre. When the mixture is allowed to cool, the $\mathrm{Ph}_{2} \mathrm{Se}_{2}$ precipitates out of the ionic liquid and forms two phases again.

For all solutions it was found that the reaction was completed after just $1 \mathrm{~min}$ in a microwave reactor. In various sets of experiments, the influence of the following factors:

- reaction temperature,

- ionic liquid cation,

- dilution with an 'inert' ionic liquid,

- speciation of the ionic liquid anionon the composition and morphology of indium(III) selenide microcrystals was studied.

\section{The influence of temperature}

In the first set of experiments, solutions of $\mathrm{Ph}_{2} \mathrm{Se}_{2}$ in four

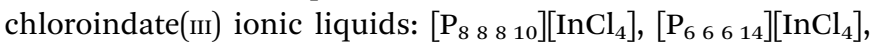
$\left[\mathrm{P}_{6} \begin{array}{lll}6 & 6 & 17\end{array}\right]\left[\mathrm{InCl}_{4}\right]$ and $\left[\mathrm{C}_{8} \mathrm{mim}\right]\left[\mathrm{InCl}_{4}\right]$ were heated in a microwave reactor for $1 \mathrm{~min}$. For each solution, five reaction temperatures were tested: $200,210,220,240$ and $280{ }^{\circ} \mathrm{C}$. No reaction was observed under $220{ }^{\circ} \mathrm{C}$, neither by visual assessment, nor by Raman spectroscopy. For reaction temperatures of 240 and 280 ${ }^{\circ} \mathrm{C}$, the ionic liquid solutions were visibly different after the

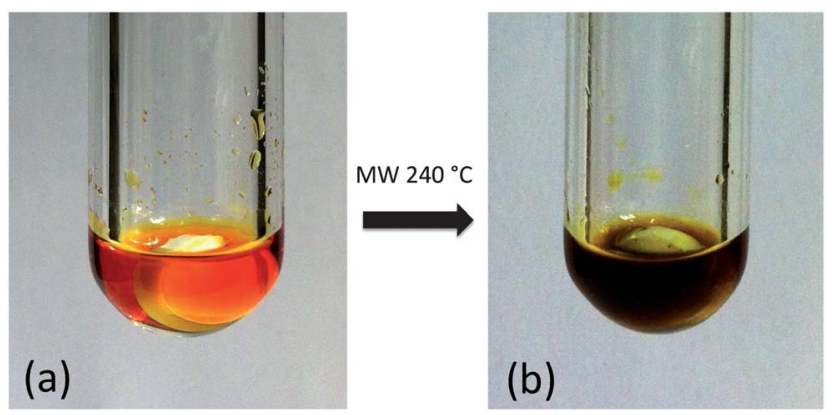

Fig. 1 Solution of diphenyl diselenide in the chloroindate ionic liquid (a) and the reaction mixture after 1 min exposure to microwave radiation at $240{ }^{\circ} \mathrm{C}$ (b).

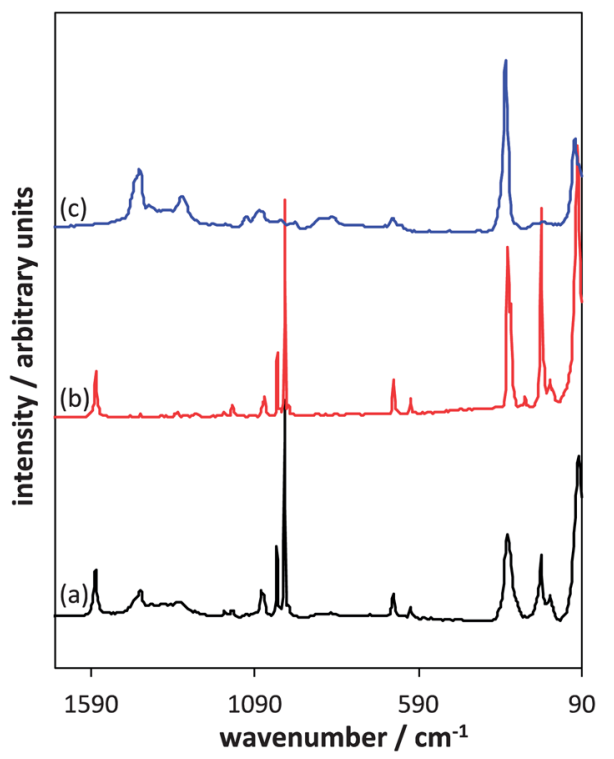

Fig. 2 Raman spectra of: the solution of $\mathrm{Ph}_{2} \mathrm{Se}_{2}$ in $\left[\mathrm{P}_{6} 6_{6}{ }_{17}\right]\left[\mathrm{InCl}_{4}\right](a)$, diphenyl diselenide (b) and neat $\left[\mathrm{P}_{6} 66_{17}\right]\left[\mathrm{InCl}_{4}\right]$ (c).

reaction: they changed from a yellow homogeneous solution to

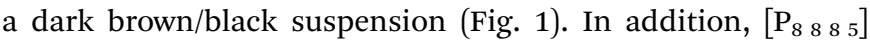
$\left[\mathrm{InCl}_{4}\right]$ was used to prepare indium(III) selenide at the previously determined optimum temperature of $240{ }^{\circ} \mathrm{C}$.

Morphologies of the microcrystals prepared at both temperatures, with different cations, were studied using SEM; furthermore, EDX was used to elucidate elemental composition and stoichiometry of the products formed (Table 1).

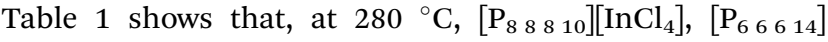

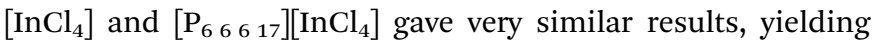
products of neither uniform nor well-defined size and morphology (Fig. 3). From the EDX analysis, for all samples prepared at $280{ }^{\circ} \mathrm{C}$, an excess of selenium relative to indium was found, which suggests the formation of polyselenides. A small amount of phosphorus was also evident, indicating the incorporation of the phosphonium cation from the ionic liquid. The weight percentages of the elements may suggest the formation of anionic selenido-indates, such as the previously reported compounds $\left[\mathrm{PR}_{4}\right]\left[\operatorname{In}\left(\mathrm{Se}_{4}\right)\right]$ or $\left[\mathrm{PR}_{4}\right]\left[\mathrm{In}_{2}\left(\mathrm{Se}_{4}\right)_{4}\left(\mathrm{Se}_{5}\right)\right]^{40}$

The main peak found in the Raman spectra for the products of reactions carried out at $280^{\circ} \mathrm{C}$ was found at $254 \mathrm{~cm}^{-1}$, which is indicative of a polyselenide (vibration formed from $\alpha$-monoclinic Se-Se) - see Fig. 4. A small peak, which corresponds to the

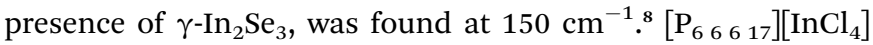
used at $280{ }^{\circ} \mathrm{C}$ produced indium selenide without organic inclusions, but the composition determined by EDX corresponded to a polyselenide structure of the $\left[\operatorname{In}(\mathrm{Se})_{4}\right]^{40}$ formula. Finally, regarding the $\left[\mathrm{C}_{8} \mathrm{mim}\right]\left[\mathrm{InCl}_{4}\right]$ ionic liquid, elemental selenium was detected, and the inclusion of the ionic liquid into the product was indicated by the presence of nitrogen in the EDX analysis.

The reaction at $240{ }^{\circ} \mathrm{C}$ using $\left[\mathrm{C}_{8} \mathrm{mim}\right]\left[\mathrm{InCl}_{4}\right]$ resulted in both elemental selenium and an indium selenide compound (with stoichiometry close to $\operatorname{In}_{2} \mathrm{Se}_{3}$ ) present in the final product. In contrast, the phosphonium ionic liquids tested at $240{ }^{\circ} \mathrm{C}$ gave 
Table 1 Morphology and average composition of indium selenide products synthesised in different ionic liquids, at two temperatures; in some cases, several distinctive products were detected in one sample

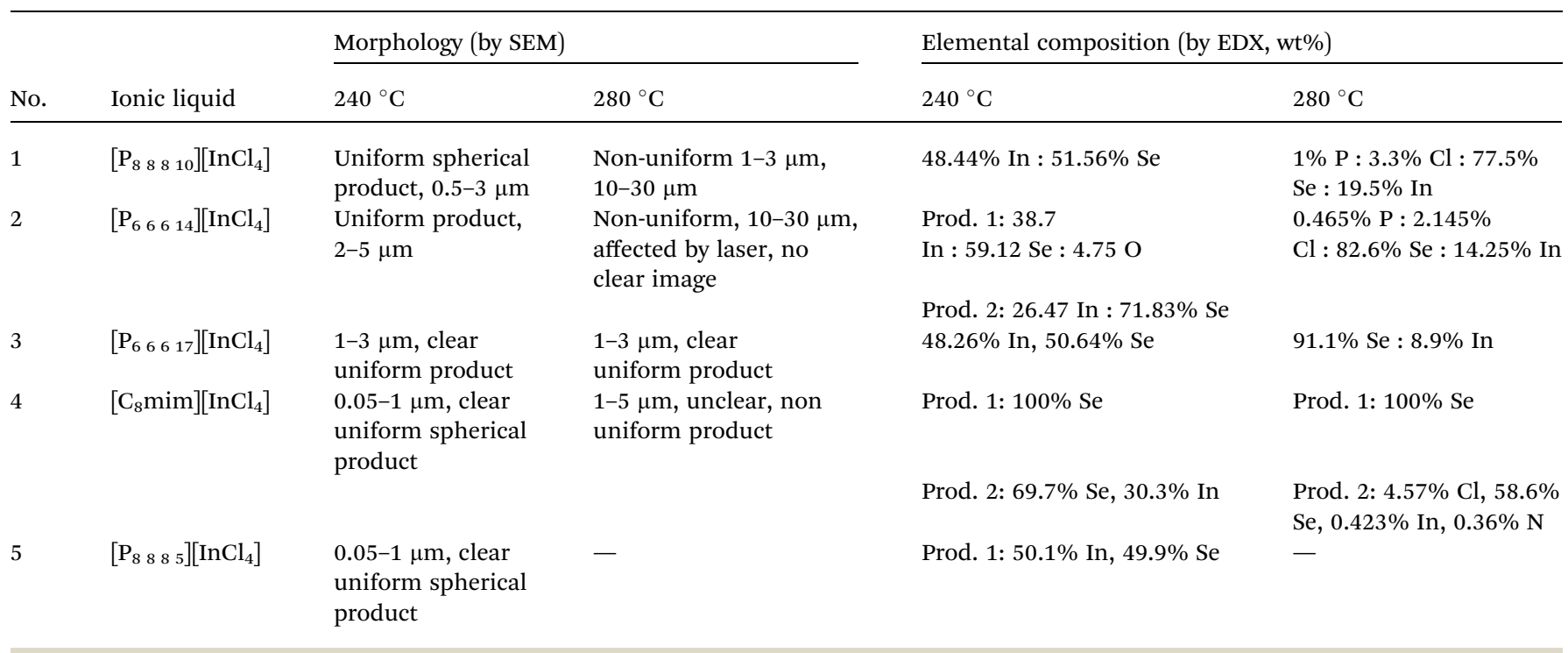

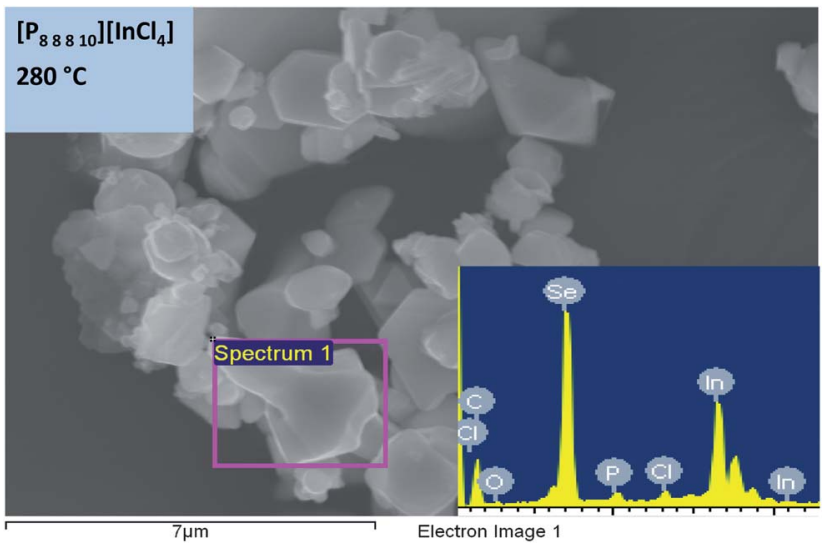

Fig. 3 SEM image and EDX spectrum of the material prepared using $\left[\mathrm{P}_{8} 8\right.$ \& 10$]\left[\mathrm{InCl}_{4}\right]$ at $280{ }^{\circ} \mathrm{C}$.

products containing exclusively indium and selenium in various stoichiometries, in the absence of any 'contamination' by the ionic liquid cation. In particular, $\left[\mathrm{P}_{8} \mathbf{8}_{8}{ }_{10}\right]\left[\mathrm{InCl}_{4}\right]$,

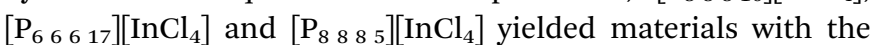
In : Se weight ratio very close to the desired $\mathrm{In}_{2} \mathrm{Se}_{3}$, which is $51 \%$ In : $49 \%$ Se, with a clear uniform microcrystalline morphology

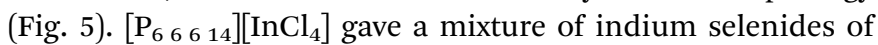
varying stoichiometries. Building on these observations, $240{ }^{\circ} \mathrm{C}$ was selected as the optimum temperature for further studies.

\section{The influence of ionic liquid cation}

The study revealed that with varying temperatures, the cation had a marked influence on both composition and morphology of the product, which is in agreement with the literature. ${ }^{30-32}$ The $\left[\mathrm{C}_{8} \mathrm{mim}\right]^{+}$cation yielded materials of poor morphology and composition, irrespective of the reaction temperature, while the phosphonium cations appeared to yield materials of uniform

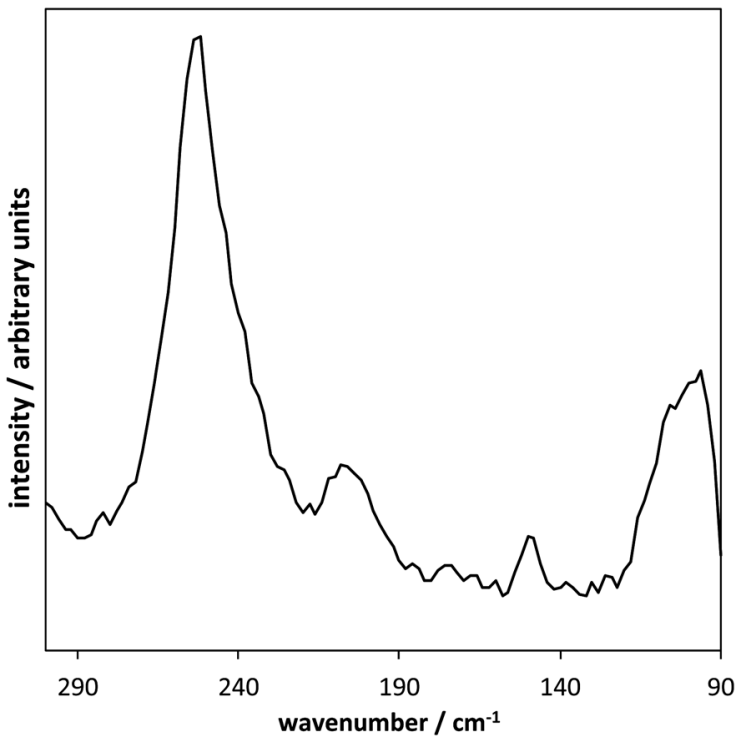

Fig. 4 Raman spectrum of a polyselenide formed after the reaction of

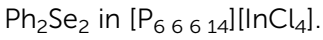

morphology. Phosphonium ionic liquids have numerous advantages over the imidazoloium based analogues, including a greater stability (thermal, chemical and electrochemical), a larger electrochemical window, and a lower cost. They also have a lower viscosity than ammonium analogues, with small amounts of dilutants having a profound effect on the viscosity of the ionic liquids under investigation. ${ }^{41}$

\section{The influence of dilution with a spectator ionic liquid}

It was established that using a reaction temperature of $240{ }^{\circ} \mathrm{C}$,

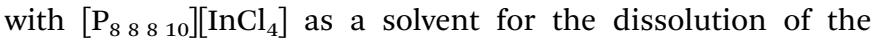
selenium precursor, the optimum conditions to prepare 


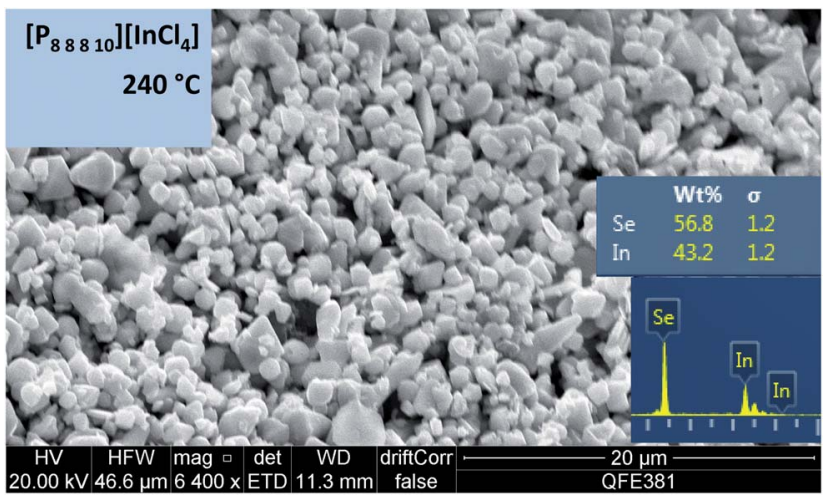

Fig. 5 SEM image and EDX spectrum of the material prepared using $\left[\mathrm{P}_{8} 8\right.$ \& 10$]\left[\mathrm{InCl}_{4}\right]$ at $240{ }^{\circ} \mathrm{C}$.

indium(III) selenide are achieved. In attempt to further investigate the control of the morphology of the products, the influence of dilution was investigated.

The solution of $\mathrm{Ph}_{2} \mathrm{Se}_{2}$ in $\left[\mathrm{P}_{8} 8\right.$ 8 10 0 $]\left[\mathrm{InCl}_{4}\right]$ was diluted with

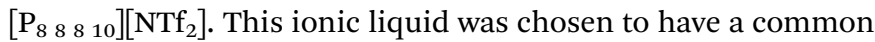
cation with the chloroindate(III) precursor and an almost inert, weakly coordinating anion. The dilutions were prepared in two mass ratios: $1: 1$ and $1: 2$. The SEM-EDX results showed that, in addition to reducing the product size from microcrystalline to nanosize, the stoichiometry was compromised and resulted in the production of a polyselenide, which is undesirable for the use in semiconductor applications. The reaction was also

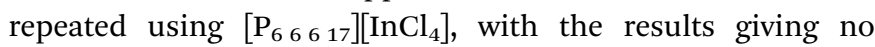
benefits to the current reaction, the morphology remained the same, with a detrimental effect on the stoichiometry.

\section{The influence of ionic liquid anion}

Another set of reactions was carried out to investigate the effect of the anion on the stoichiometry of the product as well as its size and morphology. Besides tetrachloroindate(III), two other chloroindate(III) anions are known: ${ }^{28}\left[\mathrm{InCl}_{5}\right]^{2-}$ and $\left[\mathrm{InCl}_{6}\right]^{3-}$. Ionic liquids based on these anions were formed using $\left[\begin{array}{llll}\mathrm{P}_{6} & 6 & 6 & 14\end{array}\right] \mathrm{Cl}$ and appropriate stoichiometries of $\mathrm{InCl}_{3}$. Solutions of $\mathrm{Ph}_{2} \mathrm{Se}_{2}$ in the two chloroindate(III) ionic liquids,

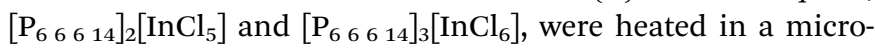
wave for $1 \mathrm{~min}$. For each solution, six reaction temperatures were tested: $200,210,220,240,260$ and $280^{\circ} \mathrm{C}$. In both cases, no reaction was detected between 200 and $260{ }^{\circ} \mathrm{C}$, neither judging by the appearance of the solution nor by Raman spectroscopy. At $280{ }^{\circ} \mathrm{C}$, the products were suspensions of dark brown/black powder in an ionic liquid. The precipitate obtained was analysed by SEM/EDX, Raman spectroscopy and PXRD.

The Raman spectra of both products prepared at $280^{\circ} \mathrm{C}$ (see Fig. 6) indicated that indium(III) selenide was formed, with the distinct peak found at $150 \mathrm{~cm}^{-1}$, which is characteristic of $\gamma$ $\mathrm{In}_{2} \mathrm{Se}_{3}$.

The SEM/EDX analysis show that for the reaction involving

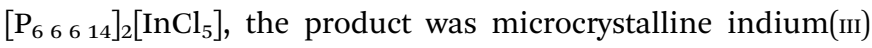
selenide, with a uniform size and morphology (Fig. 7). When

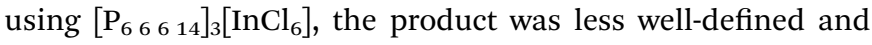

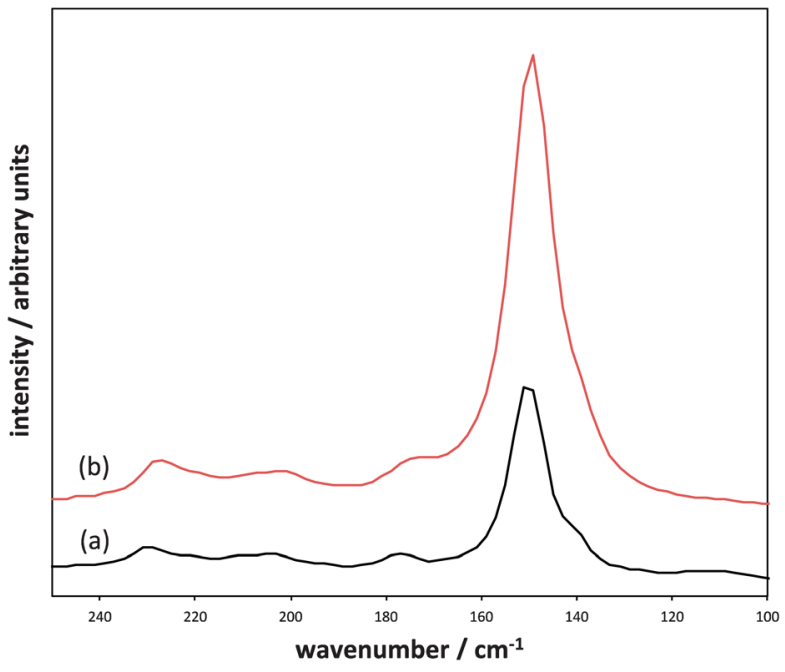

Fig. 6 Comparison of Raman spectra of the products formed when using $\left[\mathrm{P}_{6} \sigma_{6}{ }_{14}\right]_{3}\left[\mathrm{lnCl}_{6}\right]+\mathrm{Ph}_{2} \mathrm{Se}_{2}$ (a) and product formed when using $\left[\mathrm{P}_{6} \begin{array}{lll}6 & 6 & 14\end{array}\right]_{2}\left[\mathrm{lnCl}_{5}\right]+\mathrm{Ph}_{2} \mathrm{Se}_{2}(\mathrm{~b})$.

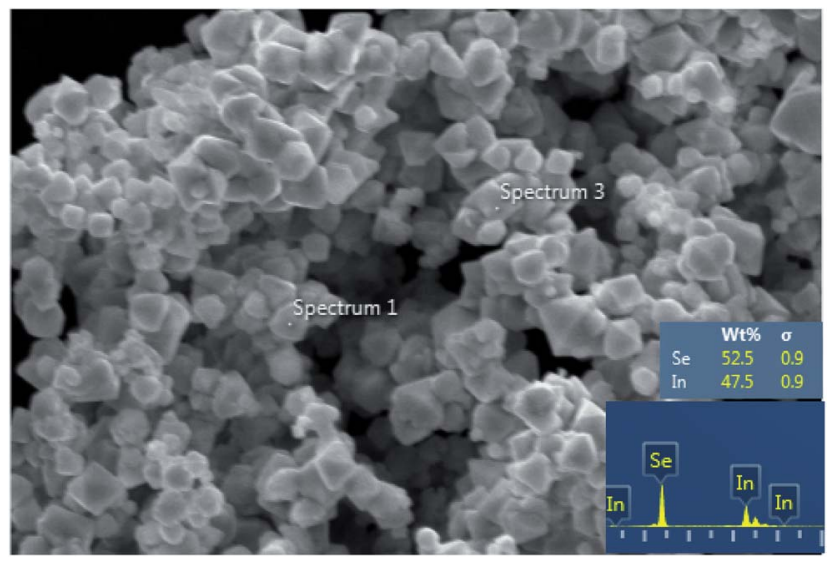

Fig. 7 SEM image and EDX spectrum of the material prepared using $\left[\mathrm{P}_{6} 6{ }_{14}\right]_{2}\left[\mathrm{lnCl}_{5}\right]$ at $280^{\circ} \mathrm{C}$.

contained two materials of varying ratios of In : Se, with the bulk of the material formed being $\operatorname{In}_{2} \mathrm{Se}_{3}$.

These results indicate that aside from changing the phosphonium cation, also the anion can be varied in order to produce the desired stoichiometry of the indium selenide product. As shown above, many of the tested cations produced $\mathrm{In}_{2} \mathrm{Se}_{3}$ at $240{ }^{\circ} \mathrm{C}$, but with $\left[\mathrm{P}_{6} 6_{6}{ }_{14}\right]\left[\mathrm{InCl}_{4}\right]$ it was not possible.

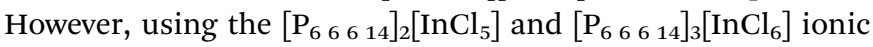
liquids, and applying a higher temperature of $280^{\circ} \mathrm{C}, \mathrm{In}_{2} \mathrm{Se}_{3}$ was successfully synthesised.

\section{Phase identification}

Powder XRD patterns for the products synthesised at $280{ }^{\circ} \mathrm{C}$ showed no resemblance to any indium selenide polymorph, or to any known polyselenides. N.B., there was only one published example of a polyselenide containing indium, selenium and phosphorus, of the stoichiometry $\operatorname{In}_{4} \mathrm{P}_{6} \mathrm{Se}_{18}$, and its XRD pattern 
differed greatly from the products formed at $280{ }^{\circ} \mathrm{C}$. In contrast, samples prepared at $240{ }^{\circ} \mathrm{C}$ in ionic liquids based on the

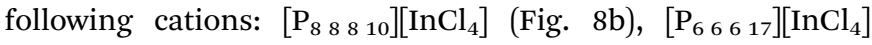
(Fig. 8c), [ $\left[\begin{array}{lll}\mathrm{P}_{8} & 8 & 8\end{array}\right]\left[\mathrm{InCl}_{4}\right]$ (Fig. 8d), gave XRD patterns in close agreement with that of the $\operatorname{In}_{2} \mathrm{Se}_{3}$ standard (Fig. 8a).

The distribution and intensities of the peaks indicate that the $\gamma$ form of $\operatorname{In}_{2} \mathrm{Se}_{3}$ has been synthesised, with the main peaks found at $27^{\circ}(006)$ and $58^{\circ}(0012) .{ }^{42}$ Moreover, the experimental

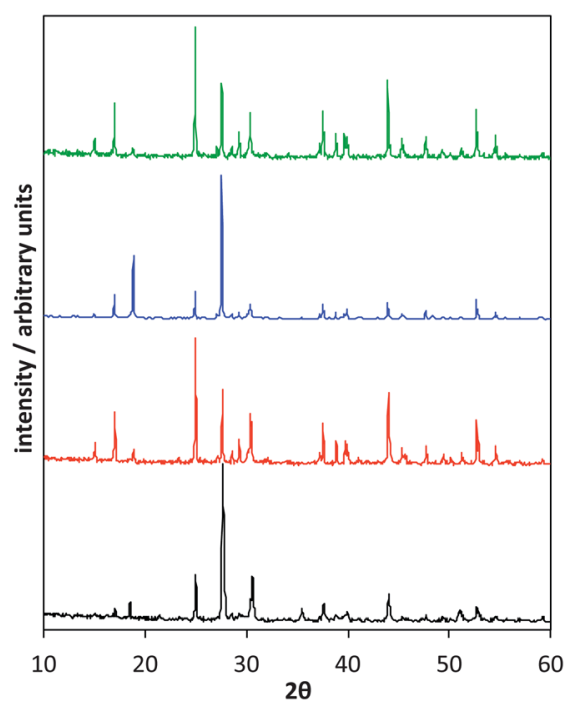

Fig. 8 Comparison of XRD spectra; $\ln _{2} \mathrm{Se}_{3}$ standard (a), products when using $\left[\mathrm{P}_{8} 88_{10}{ }_{10}\right]\left[\mathrm{InCl}_{4}\right]+\mathrm{Ph}_{2} \mathrm{Se}_{2}$ (b), $\left[\mathrm{P}_{6} 66_{17}\right]\left[\mathrm{InCl}_{4}\right]+\mathrm{Ph}_{2} \mathrm{Se}_{2}$ (c),

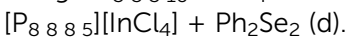

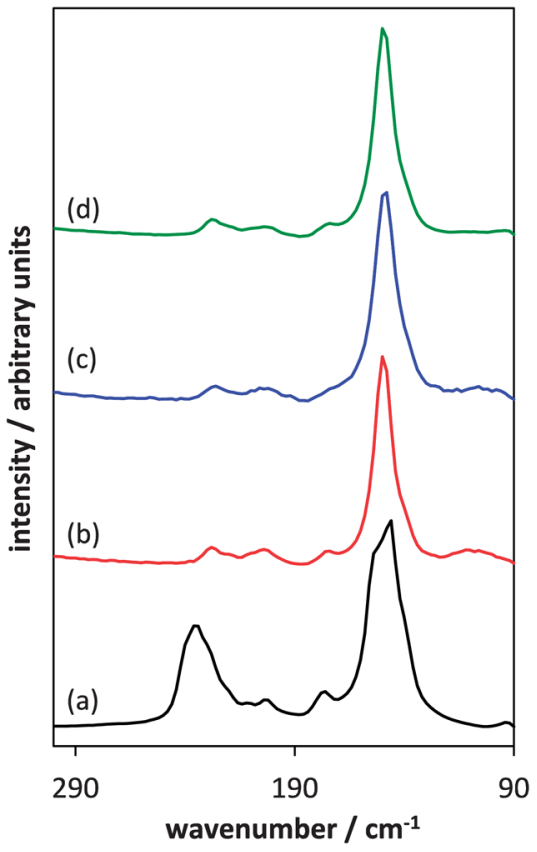

Fig. 9 Comparison of Raman spectra of the $\ln _{2} \mathrm{Se}_{3}$ standard (a), and

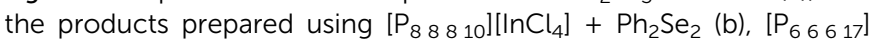
$\left[\mathrm{InCl}_{4}\right]+\mathrm{Ph}_{2} \mathrm{Se}_{2}$ (c) and $\left[\mathrm{P}_{8} 8_{8}{ }_{5}\right]\left[\mathrm{InCl}_{4}\right]+\mathrm{Ph}_{2} \mathrm{Se}_{2}(\mathrm{~d})$.
XRD patterns are identical with the simulated pattern for $\gamma$ $\mathrm{In}_{2} \mathrm{Se}_{3}$.

The Raman spectrum obtained for each of these products was in very good agreement with the XRD study, indicating the presence of $\gamma-\mathrm{In}_{2} \mathrm{Se}_{3}$. The Raman spectra of the products

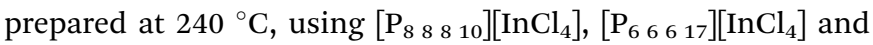
$\left[\begin{array}{llll}\mathrm{P}_{8} & 8 & 8 & 5\end{array}\right]\left[\mathrm{InCl}_{4}\right]$, featured the characteristic peak of $\gamma-\mathrm{In}_{2} \mathrm{Se}_{3}$ at $150 \mathrm{~cm}^{-1}$. This peak also matches the dominant signal found for the $\mathrm{In}_{2} \mathrm{Se}_{3}$ standard (Fig. 9). However, the purchased standard appears to be of the $\kappa-\mathrm{In}_{2} \mathrm{Se}_{3}$ form, which has a similar molecular structure to $\gamma$ - $\operatorname{In}_{2} \mathrm{Se}_{3}$, but with a more equal distribution between the peaks at $150 \mathrm{~cm}^{-1}$ and $250 \mathrm{~cm}^{-1} .8$

\section{Conclusions}

A new route towards indium(III) selenide has been successfully developed. It involves inexpensive phosphonium ionic liquids, used in a safe and green ionothermal procedure. The reaction temperature has been lowered by at least $60{ }^{\circ} \mathrm{C}$ compared to the literature methods, and the reaction time has been reduced from several hours to $1 \mathrm{~min}$, thanks to the employment of a microwave reactor. The need for organic solvents has been eliminated. To our knowledge, this is the first example of using either ionic liquids and the ionothermal approach, or microwave-based synthesis, to prepare indium(III) selenide.

From the combination of SEM, EDX, Raman and XRD studies, it is conclusive that $\gamma-\operatorname{In}_{2} \mathrm{Se}_{3}$ has been produced in each case. The novel microwave-assisted synthesis of indium(III) selenide has allowed for a more simple, less time consuming and elegant way to make this semiconductor material.

\section{Acknowledgements}

The authors would like to thank Michael Moser, Jeff Dyck and the team at CYTEC for all their support and abundance of phosphonium ionic liquid supplies and Dr John D. Holbrey for access to the microwave reactor. Dr Gabriela Adamova is

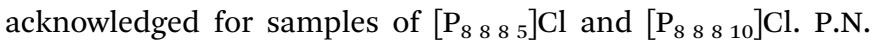
thanks the EPSRC for a RCUK fellowship.

\section{Notes and references}

1 H. M. Pathan, S. S. Kulkarni, R. S. Mane and C. D. Lokhande, Mater. Chem. Phys., 2005, 93, 16.

2 S. Yang, H. Wang, W. Fu and D. Kelley, J. Photochem. Photobiol., A, 2007, 192, 159.

3 I. H. Mutlu, M. Z. Zarbaliyev and F. Aslan, J. Sol-Gel Sci. Technol., 2007, 43, 223.

4 H. Bouzouita, N. Bouguila, S. Duchemin, S. Fiechter and A. Dhouib, Renewable Energy, 2002, 25, 131.

5 A. Chaiken, K. Nauka, G. A. Gibson, H. Lee, C. C. Yang, J. Wu, J. W. Ager, K. M. Yu and W. Walukiewicz, Appl. Phys. Lett., 2003, 94, 2390.

6 J. Ye, S. Soeda, Y. Nakamura and O. Nittono, Jpn. J. Appl. Phys., 2008, 37, 4264. 
7 J. Jasinski, W. Swider, J. Washburn, Z. Liliental-Weber, A. Chaiken, K. Nauka, G. A. Gibson and C. C. Yang, J. Appl. Phys., 2002, 81, 1.

8 C. deGroot and J. Moodera, J. Appl. Phys., 2001, 89, 4336.

9 J. J. Ning, G. J. Xiao, N. R. Xiao, L. Wang, B. B. Liu and B. Zou, J. Cryst. Growth, 2011, 336, 1.

10 P. Vaqueiro, Inorg. Chem., 2008, 47, 20.

11 A. K. Cheetham, G. Ferey and T. Loiseau, Angew. Chem., Int. Ed., 1999, 38, 3284.

12 K. Tsamartzi, J. H. Song, T. Bakas, A. J. Freeman, P. N. Trikalitis and M. G. Kanatzidis, Inorg. Chem., 2008, 47, 11920.

13 C. Wang, X. H. Bu, N. F. Zhang and P. Y. Feng, Angew. Chem., Int. Ed., 2002, 41, 1959.

14 S. M. Yang and D. F. Kelley, J. Phys. Chem. B, 2005, 109, 12701.

15 R. Sreekumar, Phys. Status Solidi B, 2013, 250.

16 J. L. Lu, Y. Xie, F. Xu and L. Zhu, J. Mater. Chem., 2002, 12, 2755.

17 P. Wasserscheid and W. Keim, Angew. Chem., Int. Ed., 2000, 39, 3772.

18 K. R. Seddon, J. Chem. Technol. Biotechnol., 1997, 68, 351.

19 J. S. Wilkes, J. A. Levinsky, R. A. Wilson and C. L. Hussey, Inorg. Chem., 1982, 21, 1263.

20 P. Nockemann, B. Thijs, S. Pittois, J. Thoen, C. Glorieux, K. Van Hecke, L. Van Meervelt, B. Kirchner and K. Binnemans, J. Phys. Chem. B, 2006, 110, 20978.

21 E. Ahmed, J. Breternitz, M. F. Groh and M. Ruck, CrystEngComm, 2012, 14, 4874.

22 E. Ahmed, A. Isaeva, A. Fiedler, M. Haft and M. Ruck, Chem.Eur. J., 2011, 17, 6847.

23 A. P. Abbott, G. Frisch, J. Hartley and K. S. Ryder, Green Chem., 2011, 13, 471.

24 E. Ahmed and M. Ruck, Coord. Chem. Rev., 2011, 255, 2892.

25 Z. Lin, D. S. Wragg, J. E. Warren and R. E. Morris, J. Am. Chem. Soc., 2007, 129, 10334.
26 D. Freudenmann, S. Wolf, M. Wolff and C. Feldmann, Angew. Chem., Int. Ed., 2011, 50, 11050.

27 J. D. Holbrey, J. Estager and M. Swadźba-Kwaśny, Chem. Soc. Rev., 2014, 43, DOI: 10.1039/C3CS60310E.

28 D. C. Apperley, C. Hardacre, P. Licence, R. W. Murphy, N. V. Plechkova, K. R. Seddon, G. Srinivasan, M. SwadźbaKwaśny and I. J. Villar-Garcia, Dalton Trans., 2010, 39, 8679. 29 A. Taubert and Z. Li, Dalton Trans., 2007, 723.

30 (a) A. Taubert, P. Steiner and A. Mantion, J. Phys. Chem. B, 2005, 109, 15542; (b) A. Taubert, C. Palivan, O. Casse, F. Gozzo and B. Schmitt, J. Phys. Chem. C, 2007, 111, 4077.

31 J. Estager, P. Nockemann, K. R. Seddon, G. Srinivasan and M. Swadźba-Kwaśny, ChemSusChem, 2011, 5, 117.

32 C. J. Serpell, J. Cookson, A. L. Thompson, C. M. Brown and P. D. Beer, Dalton Trans., 2013, 42, 1385.

33 K. Biswas, Q. Zhang, I. Chung, J.-H. Song, J. Androulakis, A. J. Freeman and M. G. Kanatzidis, J. Am. Chem. Soc., 2010, 132, 14760.

34 K. Biswas, I. Chung, J.-H. Song, C. D. Malliakas, A. J. Freeman and M. G. Kanatzidis, Inorg. Chem., 2013, 52, 5657.

35 E. Ahmed and M. Ruck, Coord. Chem. Rev., 2011, 255, 2892. 36 Z. Ma, J. Yu and S. Dai, Adv. Mater., 2010, 22, 261.

37 S. Mallakpour and Z. Rafiee, Prog. Polym. Sci., 2011, 36, 1754.

38 G. Adamová, R. L. Gardas, L. P. N. Rebelo, A. J. Robertson and K. R. Seddon, Dalton Trans., 2011, 40, 12750.

39 (a) J. Yang, P. Tian, L. He and W. Xu, Fluid Phase Equilib., 2003, 204, 295; (b) J. Yang, P. Tian, W. Xu, B. Xu and S. Liu, Thermochim. Acta, 2004, 412, 1.

40 S. S. Dhinga and M. G. Kanatzidis, Inorg. Chem., 1993, 32, 1357.

41 K. J. Fraser and D. R. MacFarlane, Aust. J. Chem., 2009, 62, 209.

42 A. M. Rasmussen, S. T. Teklemichael, E. Mafi, Y. Gu and M. D. McCluskey, Appl. Phys. Lett., 2013, 102, 062105.

43 S. J. Ewing, A. V. Powell and P. Vaquiero, J. Solid State Chem., 2011, 184, 1800. 